\title{
EL ESTILO DIRECTO EN EL ESPAÑOL ORAL A PARTIR DE UNA MUESTRA DEL ARCHIVO DE TEXTOS HISPÁNICOS DE LA UNIVERSIDAD DE SANTIAGO
}

\author{
Noelia Estévez RIONEGRO \\ Universidad de Santiago de Compostela
}

\section{INTRODUCCIÓN}

En la lengua oral, en general, y en la conversación, en particular, se generan constantes estructuras lingüísticas en las que se insertan citas y alusiones a discursos expresados por otros hablantes en diferentes contextos comunicativos o, incluso, por un mismo hablante que refiere sus propias palabras. La espontaneidad en el discurso oral le confiere al estilo directo unas características propias que lo diferencian considerablemente de las construcciones de cita en el discurso escrito, como el periodístico o el narrativo (vid. Estévez Rionegro 2009). Con la finalidad de profundizar en este aspecto concreto de la citación oral, se ha llevado a cabo un estudio de corpus, del que ha sido objeto de análisis una modesta muestra de, aproximadamente, doscientas secuencias de estilo directo en lengua oral, que refleja el habla de tres áreas lingüísticas del español peninsular y el español de América (Sevilla, Madrid y Buenos Aires). Todos los enunciados han sido extraídos de la Base de Datos Sintácticos del Español Actual, desarrollada en el departamento de Lengua Española de la Universidad de Santiago de Compostela, a partir del análisis sintáctico del Archivo de Textos Hispánicos de la Universidad de Santiago, un vasto conjunto de textos digitalizados de español contemporáneo.

A la luz del análisis realizado (centrado en construcciones de estilo directo formadas por una expresión introductora -habitualmente un verboy una secuencia reproducida) y como se detallará a lo largo del trabajo, en la lengua oral, el estilo directo se caracteriza, principalmente, por la repetición de la secuencia reproducida y del verbo que la introduce. No obstante, también existen casos en los que se produce la omisión de la expresión introductora y otros en los que se da la condensación de varias citas con una única expresión introductora. Todos ellos constituyen, en conjunto, un retrato de las posibilidades que el estilo directo ofrece en la lengua oral española y el manejo que los hablantes hacen de ellas. 


\section{Estado De La CUestión}

Varios especialistas han analizado el estilo directo en la lengua española oral, en su mayoría, a través de estudios centrados en el habla concreta de un área geográfica. Todos ellos coinciden al destacar el verbo decir como el más empleado por los hablantes para introducir secuencias de estilo directo en el discurso oral (superando, en todos los casos, las tres cuartas partes de la totalidad de los corpus empleados). Sin embargo, el enfoque de sus estudios sigue líneas diferentes.

Kvavik (1986) analiza las diferencias entonativas de los estilos directo e indirecto cuando son manifestaciones de oralidad en los textos literarios en español. El análisis muestra que, en la conversación, el estilo directo se caracteriza por una mayor expresividad y menor uniformidad de entonación, en oposición al indirecto, que es más lineal prosódicamente. El estilo directo es más real, en tanto que porta elementos entonativos que presentan características vivificadoras del discurso; en definitiva, una particular entonación propia de la construcción.

Por su parte, Cameron (1998) distingue tres tipos de uso del estilo directo en la lengua oral: casos de estilo directo introducidos por verba dicendi, casos en los que la expresión introductora equivale a «y + frase nominal» ( y ella, «iAy no, mijo!») y casos de estilo directo sin marco o freestanding quotation (Entonces me metía escapado y qué sé yo para la tienda $\emptyset$ : «¿Qué pasó?» "No tengo clase»). Entre los verbos del primer grupo, y por orden de frecuencia, el autor registra en su corpus los siguientes: decir, hacer, verbos de movimiento, gritar, preguntar/cuestionar, pensar, venir + así, quedarse, avisar, predecir, contestar, llamar, empezar y responder. Señala, además, la preferencia de los hablantes en el uso de la primera o tercera persona del singular ante las construcciones del primer y el segundo tipo.

Benavent Payá ${ }^{1}$ (2003) realiza un análisis del estilo directo en la conversación coloquial en español. Registra la predominancia de las secuencias de cita introducidas por el verbo decir en primera y tercera persona del singular del presente indicativo (presente histórico). Además, señala la abundancia de casos en los que se produce la omisión de decir, en los que la entonación es el único elemento que indica la introducción de la cita. En otras ocasiones, de acuerdo con la autora, ocurre todo lo contrario y se produce la repetición del introductor decir, de modo que su primera aparición indica la introducción de la cita pero su valor no es el mismo cuando se repite. Para la autora, las características descritas llevan a pensar que decir pierde parte de su significado verbal cuando encabeza estilo directo, "puesto que no se comporta como lo haría cualquier miembro de su ca-

\footnotetext{
${ }^{1}$ Para una mayor profundización en estas y otras cuestiones sobre el estilo directo en la lengua oral coloquial, véase Benavent Payá 2015 (tesis doctoral inédita).
} 
tegoría», sino que «tales rasgos parecen apuntar al ámbito de la conexión discursiva»(2003: 13).

Cabedo Nebot (2007) atiende a la prosodia del estilo directo en la conversación coloquial y, a través de un análisis contrastivo entre fragmentos conversacionales de estilo directo y otros sin estilo directo, establece como principal rasgo prosódico distintivo del estilo directo el tono enfático y demarcativo.

Los estudios de Gallucci (2010, 2012 y 2013) sobre el habla de Caracas también atienden al tipo de expresión introductora de estilo directo, así como a los verbos que se registran como introductores y su frecuencia de uso: decir, preguntar, ser, llamar, avisar, contar, escribir, escuchar, estar, gritar, hablar, insultar, invitar, pedir, pensar, reclamar, regañar, salir y suplicar. La autora analiza, además, los aspectos formales de la construcción, atendiendo a la posición de la cláusula de reporte (la posición final es casi excepcional en la totalidad del corpus) y la presencia u omisión de su sujeto (predomina ligeramente la primera), así como ciertos complementos que pueden aparecer en la construcción. Al igual que Cameron (1998), señala como tiempo verbal predominante el presente en modo indicativo y las personas primera y tercera del singular. La posición del verbo de reporte coincide con la preferida en español, que sigue el orden SVO.

Palacios (2014) realiza un estudio contrastivo del sistema de citas en el habla de los adolescentes en español e inglés. Los resultados obtenidos para el inglés determinan que el verbo más usado es go, seguido de say. El tercer uso más frecuente es la omisión del verbo introductor y, el siguiente, el verbo think. Se registran, además, aunque en menor número, las formas be like, like only, say like, go like, this is + subject, shout, verbos del tipo sound + like, talk + like y ask. En cuanto a la persona y tiempos verbales se verifica, nuevamente, el predominio del presente de indicativo en primera y tercera persona del singular. Por su parte, los resultados para la lengua española son semejantes a los anteriores en cuanto a la preeminencia de las formas verbales en primera y tercera persona del singular del presente de indicativo, si bien difieren en lo relativo a los introductores empleados. El más recurrente es el verbo decir, que supera la mitad del corpus manejado por el autor, al que siguen la expresión correlativa y yo / y el otro, la ausencia de introductor en la construcción y la expresión en plan. Otros verbos registrados, con menor representación, son: empezar, hacer, pensar, (ser) como, saltar, soltar, ir, ponerse, contar, coger y, por último, fórmulas como o sea o así.

Finalmente, Estellés-Arguedas (2015) trata de establecer el carácter evidencial de la configuración prosódica de las construcciones de estilo directo, a la que comúnmente se le atribuye una variedad de significados expresivos o pragmáticos que hacen referencia a la postura, la emoción, la imitación, etc. Presta especial atención a las secuencias de estilo directo sin marcas introductoras explícitas, dado que estas siempre están marcadas 
prosódicamente, y concluye que la prosodia del discurso directo también señala a la secuencia citada y, por tanto, la presencia de evidencialidad.

\section{ANÁLISIS DEL CORPUS}

A la vista de los estudios reseñados, parece ampliamente probado que los tiempos y personas verbales que predominan en las manifestaciones orales de estilo directo son el presente de indicativo en primera y tercera persona del singular, lo que no excluye la existencia de otras posibilidades, como también advierten los autores. El análisis que se muestra a continuación pretende contribuir a un retrato del estilo directo oral que atienda a esas excepciones, así como a otros aspectos formales y gramaticales de las construcciones, tanto en lo que se refiere a su configuración interna (elementos de la propia construcción) como externa (cómo se integra gramaticalmente en el contexto discursivo en el que se inserta), además del tipo de verbos empleados como introductores en la lengua oral de Buenos Aires, Madrid y Sevilla.

\subsection{Estructura formal de las construcciones}

En función de la forma presentada por las construcciones de estilo directo en la lengua oral, puede establecerse una tipología que diferencia tres grandes grupos: construcciones de estilo directo prototípico, construcciones de estilo directo con el verbo introductor omitido y construcciones de estilo directo con reduplicación del introductor.

\subsubsection{Construcciones prototípicas}

Presentan la forma típica del estilo directo, esto es, la concurrencia de un verbo introductor y un enunciado reproducido, como en el ejemplo que sigue:

(1) Inf. B.- Y yo estaba oyendo detrás de mí: «¿Cuál es la fórmula del período del péndulo, cuál es la fórmula del período del pén... del péndulo?», pero e... yo lo oía, lo oía, o sea, pa... hacia un lado, ¿no? Y todo el mundo que estaba alrededor (MADRID: 330, 25).

Resulta interesante el uso particular del verbo oír como introductor de estilo directo. Se trata de un uso habitual en el que el verbo, desde un punto de vista semántico, activa el frame de la comunicación verbal, lo que implica que, si uno oye, es porque otro dice o habla. Kerbrat-Orecchioni (1990) denomina a este fenómeno «tropo comunicacional» (1990: 93), el cual es definido por Adam y Lorda (1999) del siguiente modo: 
[...] figura propia de las interacciones verbales [que] se produce cuando uno de los locutores se dirige físicamente a un segundo locutor pero en realidad, sus palabras se orientan hacia un tercero que las oye igualmente (1999: 86-87).

Así, y de acuerdo con el primer ejemplo, este hecho implica que el hablante que reproduce el discurso no ha sido el destinatario ni el receptor directo del mismo, lo que no asegura la total fidelidad al enunciado original. De este modo, la reproducción depende, no solo de la memoria del hablante, sino también de su propia percepción de aquello que ha escuchado.

En un sentido muy diferente, resulta interesante, también, el ejemplo que sigue, que muestra la posibilidad de que el hablante introduzca un enunciado propio en medio del reproducido:

(2) Inf. B.- .. y C. cuando va a ser le dice: «Pero qué me vas a decir, nena, qué me vas a decir, nena.» Porque como la conoce desde que nació. «Si vos esas jaquecas que tenés brutales...» (BAIRES: 483, 14).

Como se puede apreciar, se produce una interrupción de la cita para introducir el emisor un comentario explicativo acerca del referente del mensaje. La secuencia de estilo directo se rompe y se retoma posteriormente sin ninguna marca introductora ni repetición del verbo. No obstante, se trata de un fenómeno poco usual en la lengua oral, donde suele predominar la reiteración del introductor en la misma construcción.

\subsubsection{Construcciones con la expresión introductora omitida}

Aunque no son los predominantes en la muestra del corpus manejada, existen enunciados de estilo directo en lengua oral que carecen de introductor. En estos casos, la expresión introductora omitida suele mantener una correlación semántica y discursiva con otra construcción de estilo directo aparecida previamente. Es habitual, sobre todo, en la reproducción de conversaciones, donde se expresa la introducción del discurso de unos participantes pero no la de otros, aunque su recuperación es sencilla a través del contexto.

(3) Inf. B.- Pues me parece que..., que te pregunta: «y en la... por la noche, ¿qué hay en el cielo?» «Las estrellas». ¿Entiendes?, así, de ese tipo de cosas, je, je!

Inf. A.- iJe, je! (MADRID: 447, 33).

Como se aprecia en el ejemplo, la secuencia carente de introductor responde a una correlación lógica de pregunta-respuesta, en la que la primera implica semánticamente la segunda, lo que hace factible la omisión de un elemento que aluda expresamente a ella, pues su sentido se capta en el contexto discursivo. 
En otras ocasiones, puede ocurrir que sean otros elementos oracionales o extraoracionales los que señalen el verbo introductor omitido, como ciertas partículas correlativas que sirven para enlazar varios enunciados referidos o distintas partes de uno mismo:

(4) Inf. A.- ... que se forma de que algo se corta ¿no? y, entonces...V... yo di la vuelta al Paraninfo en el autobús; vi que aquello estaba como muy negro, primero pensé: «no va a haber clase»; segundo: «si hay clase, yo no entro aquí, vamos... V... no me apetece, porque por ... oír una clase no me apetece que me desgracien... así, sin venir a cuento» (MADRID: 314, 11).

Existe una latencia, en este caso, del segundo verbo formalmente omitido en la correlación ordinal de los conectores discursivos: primero, segundo.

En relación con este fenómeno de omisión del verbo introductor, puede llegarse, incluso, a la inserción de una cita en el discurso a modo de acotación teatral, en la que la cita es introducida a través de una expresión introductora formada por la secuencia $y$ + frase nominal (como ya había señalado Cameron: 1998, entre otros):

(5) ... y, claro, como nosotros éramos un poco novatos en esto, pues nos quedamos quietos y digo: «claro como no hemos hecho nada, ¿verdad?» y los gri... y los sociales: «fuera»; y en vez de irnos corriendo, nos vamos andando y yo el último (MADRID: 313, 29).

\subsubsection{Construcciones de verbo introductor reduplicado}

Se trata de un rasgo muy habitual en lengua oral que es muestra de la constante repetición de la expresión introductora por parte del hablante al reproducir un discurso ajeno. Probablemente, tenga la finalidad de guiar al oyente en el contexto discursivo, recalcando la naturaleza de cada discurso (el reproducido y el propio):

(6) Inf. A.- Yo venía en el autobús, loca, ¿no? Yo digo: «Oy, ¿qué pasa, que no, que no llega esto a tiempo?», y entonces, a menos diez ya estaba aquí, ¿no?, a la puerta. He mirado así por la calle, para arriba, para abajo y vi que no estabas, digo «a lo mejor está dentro», y pasé. Y me dijo el... el señor este, dice: «No, no; no ha venido ninguna señorita todavía». Y digo: «AAh!, bueno, pues esperaré aquí» (MADRID: 420, 9).

(7) Me dice la empleada así tratándome un poco de ingenuo, ¿no? «Pero doctor -me dice- pero usted me dice que la... las llame a las patronas, pero usted no conoce y hace veinte años que yo vengo hablando con patronas ...» (BAIRES: 120, 37).

Existe, además, algún caso donde la secuencia de cita queda cercada entre dos expresiones introductoras, en una duplicación innecesaria del mismo verbo: 
(8) El otro día tuve una conversación con mi dentista que... bueno, ¿ves?, sigo para el lado que vos decías de Aristóteles porque me decía: «No, pero lo importante de la película...», decía, como quien hubiera descubierto la última interpretación, ¿no? (BAIRES: 42, 7).

Probablemente, lo que sucede en este tipo de enunciados es que la reiteración del verbo responde a la carencia, en lengua oral, del rasgo formal identificativo de estilo directo, más claro en la lengua escrita, que supone el uso de signos ortográficos (guiones, comillas, dos puntos...), ya que el contexto fónico no siempre propicia por sí mismo el aislamiento formal de la secuencia reproducida y es la repetición de la forma introductora la que marca la inserción de la cita.

\subsection{Aspectos gramaticales internos de las construcciones}

En virtud de los rasgos gramaticales internos de las construcciones de estilo directo, se ha establecido una triple línea de análisis que atiende a la posición de la expresión introductora y el enunciado reproducido en la construcción, los elementos que conforman la expresión introductora y los elementos del enunciado reproducido.

\subsubsection{Posición de los miembros de la construcción}

En los enunciados de estilo directo en lengua oral, se produce la anteposición de la expresión introductora en casi el 100\% de los casos y, en las pocas excepciones registradas, el introductor aparece interpuesto.

Obsérvense, a modo de ilustración, los siguientes casos, en los que el primero constituye un ejemplo prototípico y, el segundo, uno excepcional:

(9) ... el asistente diariamente le pregunta: «¿Cómo te va con tu chica?».

Inf. B.- Claro- claro.

Inf. A.- Y el tipo tiene que decir: «Es muy buena», nada más.

(BAIRES: 39, 11).

(10) ... «Muy bien -le dice el tipo- yo vengo a buscar a Pedro Páramo» (BAIRES: 417, 24).

La razón de escoger el orden lógico de la secuencia (expresión introductora-reproducción del enunciado) en el discurso oral y espontáneo tiene que ver con la intención del hablante de marcar la secuencia de cita, dando primacía a la expresión que la introduce e intentando propiciar el inmediato reconocimiento de la misma por parte del oyente. Se persigue, por tanto, una finalidad informativa y funcional y no estilística. 


\subsubsection{Elementos de la expresión introductora}

En los enunciados de estilo directo en discurso oral analizados, el segmento de la construcción que constituye la expresión introductora está formado, normalmente, por un verbo en forma personal y un sujeto que puede estar expresado u omitido. Es habitual, también, la expresión del complemento indirecto, a través de un pronombre átono que señala al receptor del mensaje. En este caso y por cuestiones de extensión, se restringe el análisis al verbo introductor y el sujeto, dejando al margen el resto de complementos.

\subsubsection{Sujeto de la expresión introductora}

Puede darse la presencia o ausencia del sujeto en la expresión introductora. Sin embargo, predominan, notablemente, los casos de sujeto omitido. Los hablantes suelen hacer hincapié y marcar la introducción de la cita con la expresión del verbo introductor, pero no dan tanta importancia a la manifestación de la fuente concreta; no importa quién lo haya dicho, sino que algo haya sido emitido por el propio hablante o por otro interlocutor, independientemente de su identidad.

En los casos de cita pospuesta en los que el sujeto se expresa, lo hace anteponiéndose al verbo, a no ser que exista algún elemento en el enunciado introductor que obligue a su posposición (como la existencia de un sujeto indeterminado o la presencia de elementos como adverbios, conjunciones o marcadores discursivos).

De acuerdo con el corpus manejado, en la lengua oral, existen cuatro posibilidades de configuración de las construcciones de estilo directo:

- Casos de sujeto implícito en el esquema formal «cita - expresión introductora - cita»:

(11) «Mirá, sí -le digo- me porté tan mal, tan mal que casi te podría llegar a decir que si tiene la faja de honor de la Sade la tiene por mí» (BAIRES: 341, 14).

- Casos de sujeto implícito en el esquema formal «expresión introductora - cita»:

(12) No tienen vocabulario. Hoy me ha pasado en preu, perdón, en C.O.U., tres o cuatro palabras, las traducen. Dije: «no, no es eso; es que eso es la palabra española» (SEVILLA: 257, 19).

- Casos de sujeto explícito antepuesto en el esquema formal «expresión introductora [sujeto-verbo] - cita»:

(13) Ella le dice: «Nita, ¿no tendrás alego en un... en las muelas?»

(BAIRES: 475,5 ). 
- Casos de sujeto explícito pospuesto en el esquema formal «expresión introductora [verbo-sujeto] - cita»:

(14) Y entonces un día me dice un señor: «Usted se extrañará, nosotros le preguntamos, pero donde va él se pesca» (BAIRES: 468, 34).

Cabe señalar que los casos de posposición del sujeto pueden explicarse por los rasgos internos de la cláusula introductora, como en el ejemplo anterior la presencia del elemento temporal entonces en posición preverbal y el empleo de un sujeto no determinado. En la lengua oral casi todas las expresiones introductoras preceden a la cita, en cuyo caso el orden normal es el de la anteposición del sujeto. Sin embargo, cuando la expresión introductora se incrusta en la cita o la sigue, lo normal es la posposición del sujeto, a no ser, como ocurre en este caso, que existan elementos en el enunciado introductor que provoquen su posposición.

Resulta interesante atender a la posición del sujeto de la expresión introductora no solo respecto al verbo introductor sino también con respecto a la cita, en tanto que permite observar su comportamiento ante la movilidad de la expresión introductora en la construcción. Sin identificarse con una estructura clausular, las construcciones de estilo directo se comportan igual que las cláusulas con tema marcado en cuanto a la posición del sujeto con respecto al resto de los miembros, lo que demuestra la cohesión discursiva de la estructura del estilo directo.

\subsubsection{Verbo de la expresión introductora}

Junto a los casos más típicos de estilo directo en los que el introductor es una forma personal del verbo, existen ejemplos en los que el verbo se expresa en forma no personal. En la muestra manejada, se registran varios casos en los que el verbo introductor está expresado en gerundio, como muestran los siguientes ejemplos:

(15) Primero se tortura un poco, anda de acá para allá, no sabe muy bien si... si se debe vengar o no. Reacciona diciendo: «No, no tengo que vengarme.» Después decide y va, lo busca, prepara un fierro, hace todo [sic] una cosa muy preparada y finalmente lo golpea terriblemente al chico (BAIRES: 438, 41).

(16) ... me mortificaba tanto y me hacía la burra como yo diciendo: «No soy la madre de este chico.» ¿No? [risas] Esté... pero como en Pinamar se sabe todo ya sabían que era el... que era hijo mío (BAIRES: 468, 30).

Por otra parte, atendiendo al modo verbal, se hallan en el corpus enunciados en estilo directo hipotéticos, expresados a través de formas verbales en futuro, si bien ha sido defendida de manera prácticamente unánime la 
idea de que, en una construcción de estilo directo, el enunciado reproducido constituye un discurso, formulado por un hablante en un momento y una situación comunicativa anterior, que es retomado, posteriormente, por otro que lo incorpora a su discurso. La existencia de casos en los que la cita es hipotética y no ha sido pronunciada en un momento anterior, cuestiona esta teoría tan arraigada en las gramáticas².

El estilo directo no es solamente aquello que ha sido dicho, sino también lo que podría decirse. No se trata de actos realizados, sino potencialmente realizables. De este modo, la cita no ha de ser, necesariamente, la reproducción de un enunciado anterior, sino que puede expresar una suposición de algo que probablemente podría emitirse. Obsérvense los siguientes enunciados:

(17) ... no pensarán como nosotros... porque si... ellos dicen que tienen una Lógica tridimensional, tú les dirás a lo mejor: «pero bueno Vds. o quieren adueñarse de la tierra, o no quieren, eso no hay duda»; y ellos dirán: «pues no..., a lo mejor ni queremos ni no queremos, nosotros tenemos otra categoría especial que tal» (MADRID: 58,32 ).

(18) Yo creo que puede ser que aterricen y que posiblemente si han visto ellos ...V... satélites artificiales y spugnics que salen de la tierra, habrán dicho pues hombre, ahí hay también seres racionales y entonces por eso habrán venido..., o habrán intentado rodear la atmósfera a ver qué pasa, o nos estarán estudiando desde fuera... (MADRID: 49, 9).

\subsubsection{Elementos del enunciado reproducido}

En la lengua oral, se observa la gran recursividad de la cita directa en el discurso, hasta el punto de producir enunciados de estilo directo metalingüístico, esto es, construcciones de estilo directo dentro del enunciado reproducido de una construcción mayor.

Los ejemplos que se ofrecen a continuación constituyen una muestra clara de ello: la cita llega a incorporarse a la propia cita, creando secuencias altamente polifónicas. Se trata de uno de los más altos grados de explotación de las construcciones de estilo directo, que llegan a generar en sí mismas nuevas secuencias citadas.

(19) Claro, no los entenderemos, pero...» pues no, nadie dijo nada, nadie dijo nada, le pareció muy natural, y yo pensaba «si hubiera ocurrido esto aquí en España ¿no? hubieran dicho: estos extranjeros, tal y cual ¿no?». Pues nada, nadie dijo nada (MADRID: 158, 12).

${ }^{2}$ A propósito de la caracterización del estilo directo en la tradición gramatical hispánica, puede consultarse Galluci (2017). 
(20) Y, y nada, nos metimos allí cuarenta o cincuenta personas, y nadie dijo nada en aquel momento. Y yo pensé, pues éstos pensarán: «estos extranjeros que vienen ahora aquí se meten, y nosotros para atrás»

(MADRID: 158, 6).

En otras ocasiones la «metacita» se produce a partir de una secuencia de estilo indirecto, en cuyo interior se genera otra construcción en estilo directo:

(21) Mi padre dice que como Jesucristo dice «si no bebierais el agua que yo os dé, no viviréis» (MADRID: 52, 21).

\subsection{Aspectos gramaticales externos de las construcciones}

Las construcciones de estilo directo registradas en la muestra no forman parte de estructuras sintácticas mayores, como cláusulas u oraciones, sino que, en el contexto conversacional, los hablantes tienden a la simplificación sintáctica y la sencillez discursiva, que se logra mediante la elaboración de oraciones simples y períodos breves, en oposición a la producción de los discursos escritos, tendentes a la subordinación y la longitud de períodos sintácticos.

$\mathrm{Al}$ margen de la estructura de las secuencias, cabe destacar una marcada presencia de elementos extraoracionales, muy propios de la oralidad, como el empleo abusivo de clichés del tipo este, ¿no?, eh, etc.:

(22) Y lo que me pasaba siempre ¿no? cuando decían: «¿Qué estudias?»...V... «Ciencias Naturales» ¿no? realmente que es lo que se llama también $\dot{i} n o$ ?, pues me contestaban: «Bueno ¿eso para qué sirve?» ¿no? porque pensaban con el... ciudadano que va con un cazamariposas (MADRID: 151, 20).

Asimismo, son muy frecuentes las interrupciones de las secuencias que, bien permanecen en suspenso (rasgo, también, muy característico de la lengua oral), o bien, son producto de la autocorrección del hablante:

(23) Y esté... otros días me habían dicho, qué sé yo, [........] que no, que no hay tal. Y m... entonces me... eh... «¿Por qué?», le pregunté yo (BAIRES: 430, 14).

\subsection{Formas verbales introductoras}

De acuerdo con la muestra manejada, los hablantes emplean en los actos conversacionales formas introductoras de estilo directo prototípicas (principalmente, verbos de dicción), que propician enunciados sencillos, que agilizan la locución y son más eficaces a oídos del interlocutor. La úni- 
ca forma de hacer identificable una cita en una locución oral, además de la entonación, es el empleo de expresiones introductoras prototípicas.

Los verbos registrados en la muestra corresponden a los siguientes tipos (con respecto a la clasificación semántica de los verbos de estilo directo, pueden consultarse los trabajos de Estévez Rionegro 2010 y 2016):

- Verbos declarativos: advertir, contar, contestar, decir, soltar.

- Verbos de pregunta y petición: preguntar.

- Verbos de percepción: oír.

- Verbos de pensamiento: pensar.

- Verbos discursivos: empezar.

\section{RECAPitulación}

Parece demostrado, en estudios precedentes (vid. Estévez Rionegro 2009 y 2016) que cada contexto discursivo se especializa en un tipo de configuración de las construcciones de estilo directo, donde el recurso de la cita se emplea con unos fines específicos y cuya adecuación al discurso se efectúa por medio de determinados procedimientos que, aunque semejantes entre sí, suelen ser, si no exclusivos, al menos característicos de cada uno de ellos.

De acuerdo con el tipo de manifestación lingüística, esto es, oral o escrita, las construcciones de estilo directo presentan características específicas en cuanto a su estructura formal. Así, en la lengua oral el hablante tiende a anteponer la expresión introductora a la cita (salvo excepciones concretas, todas las secuencias presentan el introductor antepuesto al enunciado reproducido). Es habitual, también, la omisión del sujeto del verbo, esto es la mención a la persona cuyo discurso se reproduce. Este hecho puede responder a la tendencia, en el discurso oral, a remarcar el discurso reproducido por medio de recursos de reiteración de las formas introductoras prototípicas, lo que produce, en el interlocutor, la inmediata identificación de la secuencia, sin importar tanto la mención al hablante original. Ello influye, además, en el tipo de verbo introductor empleado, que casi siempre pertenece a la clase semántica de los declarativos, los más prototípicos del estilo directo. Por su parte, cuando el sujeto se expresa, suele ir antepuesto al verbo. Tomando en consideración la posición del sujeto explícito con respecto al verbo y a la cita simultáneamente, la estructura habitual es la anteposición del sujeto con el esquema «expresión introductora [sujetoverbo] - cita», mientras que apenas una décima parte de los casos responde al esquema «expresión introductora [verbo-sujeto] - cita», donde el sujeto se pospone al verbo. 


\section{BIBLIOGRAFÍA}

ADAM, Jean-Michel y Clara-Ubaldina LORDA (1999): Lingüistica de los textos narrativos. Barcelona: Ariel.

Benavent Payá, Elisa (2003): «¿Por qué contamos nuestras historias cotidianas en estilo directo?», Foro Hispánico. Revista Hispánica de Flandes y Holanda 23 (= Nicole Delbecque [coord.]: Aproximaciones cognoscitivo-funcionales al español), Ámsterdam/Nueva York: Rodopi, 11-20.

- (2015): Decir y discurso directo en los relatos de la conversación coloquial, Tesis doctoral, Valencia: Unversitat de València.

CAMERON, Richard (1998): «A variable syntax of speech, gesture, and sound effect: Direct quotations in Spanish», Language Variation and Change 10, 43-83.

Cabedo Nebot, Adrián (2007): «Caracterización prosódica del estilo directo de habla en la conversación coloquial», Estudios de lingüistica: ELUA 21, 53-64.

Estellés-ARguedAS, María (2015): «Expressing evidentiality through prosody? Prosodic voicing in reported speech in Spanish colloquial conversations», Journal of Pragmatics 85, 138-154.

EstÉvez Rionegro, Noelia (2009): «La adecuación de la cita al contexto. Estudio comparativo de los procedimientos de estilo directo en el discurso periodístico y narrativo». En J. Serrano Alonso y A. de Juan Bolufer (coords.), Actas del Congreso Internacional de Literatura Hispánica y prensa periódica (1875-1931), Santiago de Compostela: Universidade de Santiago de Compostela - Servizo de Publicacións e Intercambio Científico, 801-811.

- (2010): «Algunas consideraciones en torno a las construcciones de estilo directo en español». En J. Sueiro Justel et alii (eds.), Lingüistica e hispanismo, Lugo: Axac, 195-210.

- (2016): Las construcciones de estilo directo en español. Estudio de corpus, Tesis doctoral, Santiago de Compostela: Universidade de Santiago de Compostela.

Gallucci, María José (2010): Discurso directo y discurso indirecto en el habla de Caracas, Tesis de Magister, Caracas: Universidad Central de Venezuela.

- (2012): «Sintaxis de las citas en estilo directo e indirecto con verbo en el habla caraqueña», Lingüistica 28, 223-246.

- (2013): «Más sobre el estilo directo e indirecto en el español de Caracas», Lengua y Habla 17/1, 89-117.

- (2017): «El discurso referido en la tradición gramatical hispánica», Cuadernos de lingüística de El Colegio de México 4/2, 213-256.

Kerbrat-Orecchioni, Catherine (1990): Les interactions verbales I, París: Armand Colin.

KVAVIK, Karen H. (1986): «Characteristics of direct and reported speech prosody: Evidence from Spanish», en Florian Coulmas (ed.), Direct and Indirect Speech, Berlín/Nueva York/Ámsterdam: Mouton de Gruyter, 333-360. 
Palacios Martínez, Ignacio Miguel (2014): «The quotative system in Spanish and English youth talk. Contrastive corpus-based study», Miscelanea. A Journal of English and American Studies 49, 95-114.

\section{RELACIÓN DE TEXTOS CITADOS}

[BAIRES] BARRENEcheA, Ana María (ed.) (1987): El habla culta de la ciudad de Buenos Aires. Materiales para su estudio (tomo 2), Buenos Aires: Instituto de Filología y Literatura Hispánicas Doctor Amado Alonso.

[MADRID] Esgueva, Manuel y Margarita CANTARero (eds.) (1981): El habla de la ciudad de Madrid. Materiales para su estudio. Madrid: CSIC.

[SEVILla] PInEdA, Miguel Ángel de (ed.) (1983): Sociolingüistica andaluza 2. Material para el estudio del habla urbana culta de Sevilla. Sevilla: Universidad de Sevilla. 